\title{
Herpesvirus in cutaneous fibropapillomas of the green turtle Chelonia mydas
}

\author{
Elliott R. Jacobson ${ }^{1}$, Claus Buergelt ${ }^{1}$, Bruce Williams ${ }^{2}$, Richard K. Harris ${ }^{2}$ \\ ${ }^{1}$ College of Veterinary Medicine, University of Florida, Gainesville, Florida 32610, USA \\ ${ }^{2}$ Department of Veterinary Pathology, Armed Forces Institute of Pathology, Washington, D.C. 20306, USA
}

\begin{abstract}
Two juvenile green turtles Chelonia mydas with multiple cutaneous and ocular fibropapillomas were evaluated. Both turtles were anesthetized and fibropapillomas were surgically removed and examined by light microscopy. Turtle No. 1 died postsurgically and was necropsied. Turtle No. 2 recovered and was anesthetized $3 \mathrm{wk}$ later to remove remaining fibropapillomas. Three weeks after the second surgery, Turtle No. 2 died and was necropsied. Histopathologic evaluation of hematoxylin and eosin stained sections of fibropapillomas of both turtles revealed areas of ballooning degeneration of epidermal cells associated with eosinophilic intranuclear inclusions. By electron microscopy, inclusions consisted of virus-like particles measuring 77 to $90 \mathrm{~nm}$. Envelopment of these particles was observed at the nuclear membrane and mature enveloped particles measuring 110 to 120 nm were present in the cytoplasm. Based upon morphology, size, and location the particles were compatible with those of the family Herpetoviridae.
\end{abstract}

\section{INTRODUCTION}

While relatively few types of tumors have been reported in chelonians (Jacobson 1981), fibropapillomas are commonly encountered in free ranging green turtles Chelonia mydas (Jacobson et al. 1989). Green turtle fibropapilloma (GTF) was first described in green turtles from the Florida Keys (USA) in 1938 (Lucke 1938, Smith \& Coates 1938) and almost $50 \mathrm{yr}$ later from green turtles in Hawaii (Balazs 1986). Based upon anecdotal reports of fishermen, GTF was seen around 1900 in Florida (Ehrhart pers. comm.) and in 1958 in Hawaii (Balazs pers. comm.). One of us (E.R.J.) has been informed by sea turtle biologists that GTF has been seen in near-shore sites in: Puerto Rico, Cayman Islands, Virgin Islands, Barbados, Venezuela, Colombia, Panama, Belize, and Australia. Over the last $10 \mathrm{yr}$ there has been an increased incidence of GTF in the Indian River Lagoon System of east central Florida (Jacobson et al. 1989) and Hawaii (Balazs pers. comm.).

The light- and electron-microscopic characteristics of GTF have recently been described (Jacobson et al. 1989). The earliest lesions exhibited ballooning degeneration of basal epidermal cells, with intracytoplasmic vacuoles occasionally containing particles with electron-dense centers; the nature of these particles could not be determined. Molecular studies using cloned mammalian papillomavirus probes failed to identify members of this group of viruses in GTF. While spirorchid trematode eggs are commonly observed within dermal capillaries (Smith \& Coates 1939), tumors without eggs have also been observed and the role of these parasites in the development of GTF has been questioned (Jacobson et al. 1989). The etiology of GTF remains unknown.

This paper presents preliminary evidence of herpesvirus involvement in GTF.

\section{METHODS AND MATERIALS}

Two juvenile green turtles Chelonia mydas, found in a debilitated condition in the vicinity of Key West, Florida, USA, were transported by air to the Veterinary Medical Teaching Hospital, University of Florida, Gainesville, Florida, for clinical evaluation. Turtle No. 1 was estimated to be 3 to $4 \mathrm{yr}$ old and weighed $8 \mathrm{~kg}$. It was submitted with generalized cutaneous fibropapillomatosis involving multifocal areas of the soft integument, periocular tissues and corneas. The turtle was anesthetized with a tiletamine/zolazepam combination (Telazol, A. H. Robbins, Richmond, VA, USA), given intramuscularly at $15 \mathrm{mg} \mathrm{kg}^{-1}$ body weight. 
Following anesthesia, the turtle was intubated and manually ventilated at 6 breaths $\mathrm{min}^{-1}$. Cryosurgery was performed on 2 large tumors on the cervical integument and tumors on the corneas were removed by keratectomy. Following surgery, ventilation was continued until the turtle started lifting its head and moving its limbs. However, at $10 \mathrm{~h}$ following injection of the anesthetic agent, the turtle became visibly depressed and apneic, and died 2 h later. Subsequently, it was submitted for necropsy. Three cutaneous fibropapillomas and multiple visceral tissues were fixed in neutral buffered $10 \%$ formalin, embedded in paraffin, sectioned at $6 \mu \mathrm{m}$, and stained with hematoxylin and $\operatorname{eosin}(\mathrm{H} \& \mathrm{E})$.

Turtle No. 2 was estimated to be 3 to 4 yr old and weighed $11 \mathrm{~kg}$. It also had generalized cutaneous fibropapillomatosis involving both the soft and hard integument, periocular tissues, and corneas. The turtle was anesthetized with ketamine hydrochloride (Ketaset, Aveco, Fort Dodge, IA, USA), given intramuscularly at $15 \mathrm{~kg} \mathrm{~kg}^{-1}$ body weight. Once immobilized, it was intubated and administered an isoflurane (Forane, Anaquest, Madison, WI, USA) in oxygen mixture. Fourteen fibropapillomas were surgically removed and bisected. Half of each tumor was placed in neutral buffered $10 \%$ formalin, embedded in paraffin, sectioned at $6 \mu \mathrm{m}$ and stained with $\mathrm{H} \& \mathrm{E}$. The corresponding half of each tumor was placed individually in a plastic bag and frozen in an ultra-freezer at $-70^{\circ} \mathrm{C}$. Following surgery, the turtle recovered without any complications. Three weeks later the turtle was again anesthetized and, utilizing a laser technique, 2 broad-based fibropapillomas were removed from the pericloacal region. Although the turtle recovered from anesthesia, it became anorexic and died 3 wk later A necropsy was performed and multiple tissues were fixed in neutral buffered $10 \%$ formalin, embedded in paraffin, sectioned at $6 \mu \mathrm{m}$ and stained with $H$ \& $E$.

A piece of formalin-fixed paraffin-embedded fibropapilloma from Turtle No. 1 was removed from the block, post-fixed in osmium tetroxide, and embedded in effapoxy resin (Ernest F. Fullam, Inc., Latham, NY, USA). Thin section were stained with toluidine blue and examined by light microscopy. Ultrathin sections (800 nm) were placed on copper grids, stained with uranyl acetate and lead citrate, and examined with an electron microscope.

\section{RESULTS}

\section{Gross pathology}

At necropsy, Turtle No. 1 had ca $500 \mathrm{ml}$ of clear, dark red fluid in the coelomic cavity. The gastrointestinal serosa, the surfaces of the liver, spleen, kidney, pericardium, and the fasicles of the skeletal muscle were surrounded by edema fluid. Trematode eggs were observed on light microscopic examination of a fecal sample.

The coelomic cavity of Turtle No. 2 contained a small amount of clear fluid. The surface of the right kidney had a few small discrete white, firm foci, which extended into the inner cortex; the largest focus was $1 \mathrm{~mm}$ in diameter. The left kidney contained multiple, white, discrete masses ( 1 to $4 \mathrm{~cm}$ in diameter). These masses extended from the cortex into the medulla and altered the shape of the kidney. Both lungs contained small $(1$ to $2 \mathrm{~cm}$ in diameter) white, firm masses in the parenchyma.

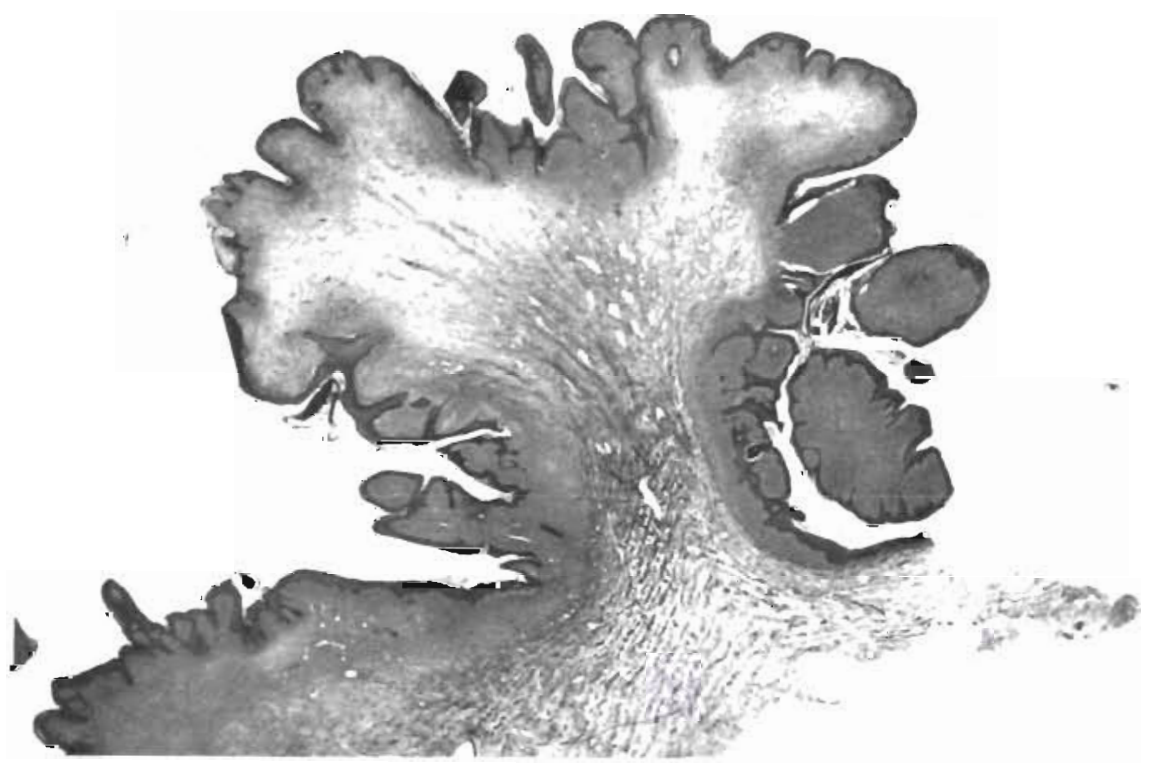

Fig. 1 Chelonia mydas. Histologic section of a cutaneous fibropapilloma of a green turtle. The fibropapilloma consists of a hyperplastic epidermis overlying a thickened dermis composed of proliferating fibroblasts and abundant loosely arranged collagen. $\mathrm{H} \& \mathrm{E}$ stain, $\times 7.5$ 


\section{A}

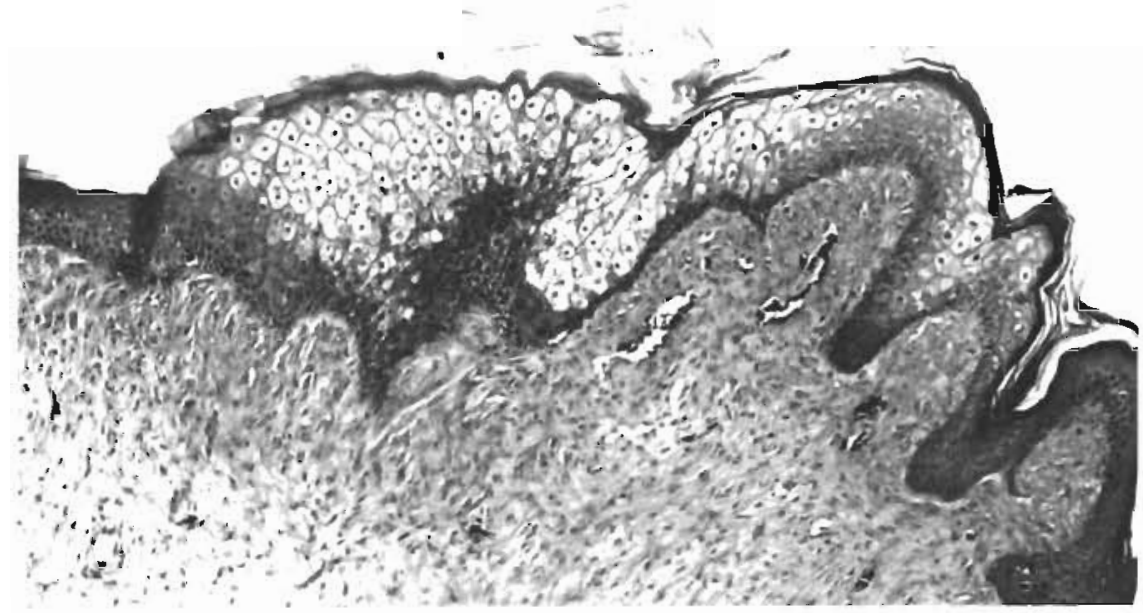

Fig. 2. Chelonia mydas. Green turtle fibropapilloma. (A) Focal area of ballooning degeneration. $H \& E$ stain, $\times 75$. (B) At higher magnification, epidermal cells can be seen to contain intranuclear viral inclusions. $H \& E$ stain, $\times 750$

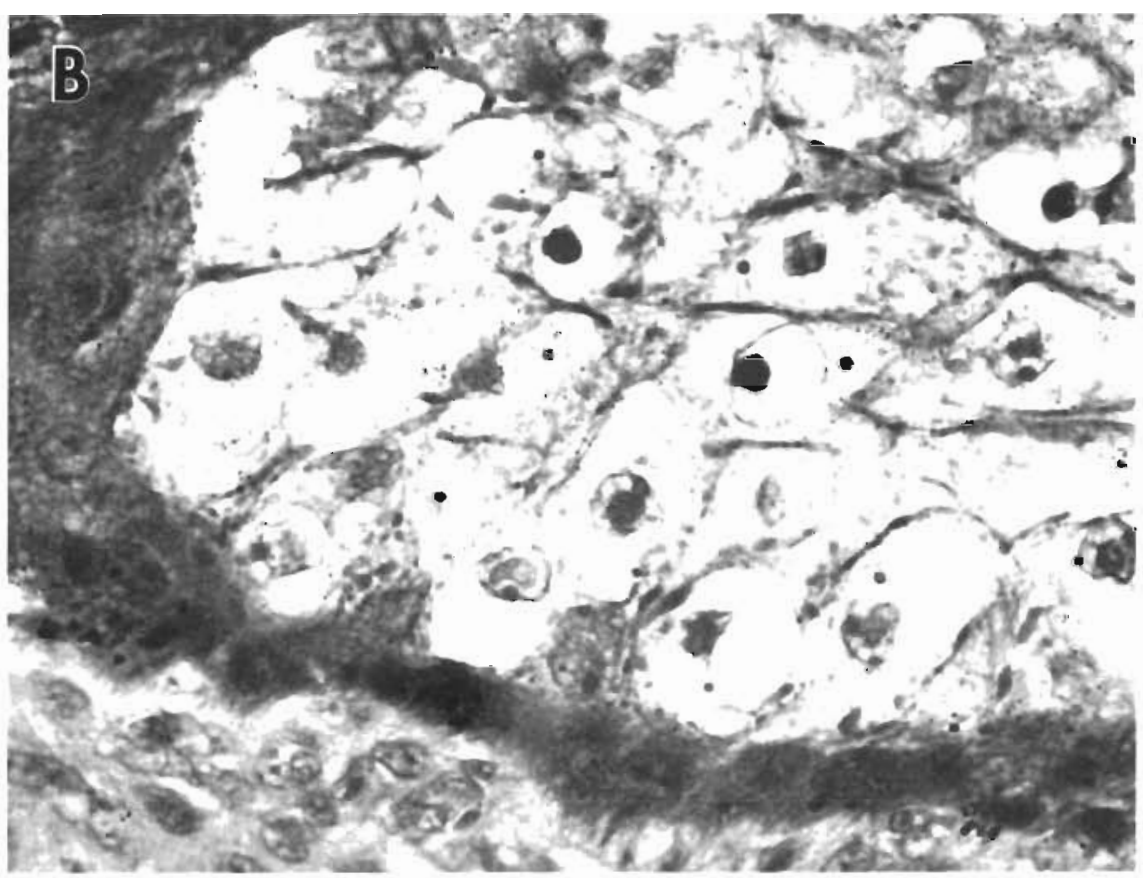

\section{Histopathology}

Histologic examination of the liver, spleen, and lung of Turtle No. 1 revealed multiple granulomas surrounding trematode eggs. The 3 cutaneous fibropapillomas examined were characterized by marked hyperplasia of the epidermis with anastomosing rete ridges extending into the dermis. The epidermis also was thrown into papillary fronds (Fig. 1) and in several foci, there was marked cytoplasmic vacuolation and ballooning degeneration of superficial epidermal cells (Fig. 2A). Many of these spongiotic cells contained eosinophilic intranuclear inclusions (Fig. 2B). The underlying dermis consisted of proliferating fibroblasts, with occasional trematode eggs within capillaries.

Histologic examination of the lung of Turtle No. 2 revealed that most of the parenchyma was replaced by hyalinized fibrous tissue. Several trematode eggs, measuring 20 to $50 \mu \mathrm{m}$, were embedded in the fibrous tissue. Eggs were also present within the interstitium of 


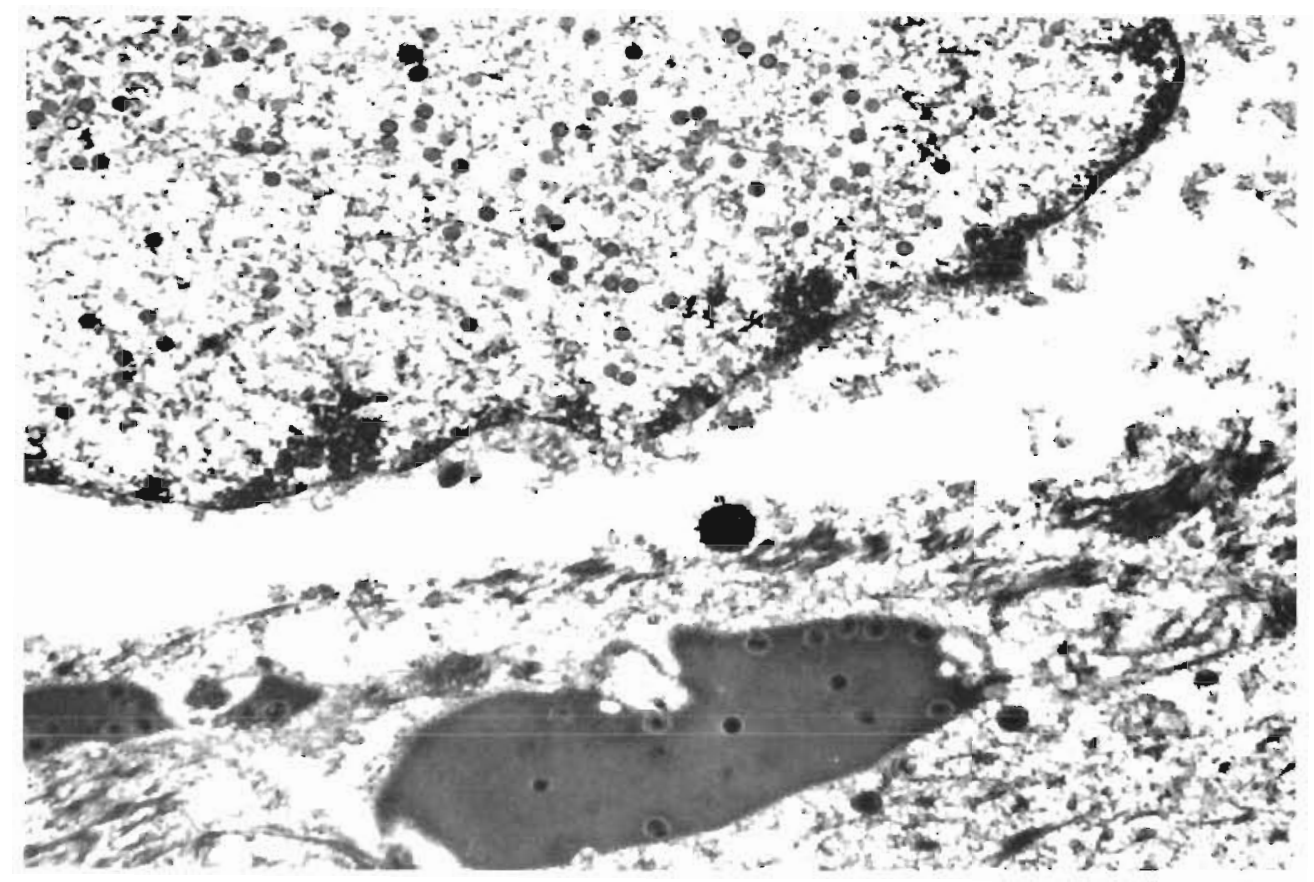

Fig. 3. Chelonia mydas. Low magnification electron micrograph showing intranuclear (I) and intracytoplasmic (C) viral particles within epidermal cells of a fibropapilloma. $\times 29575$

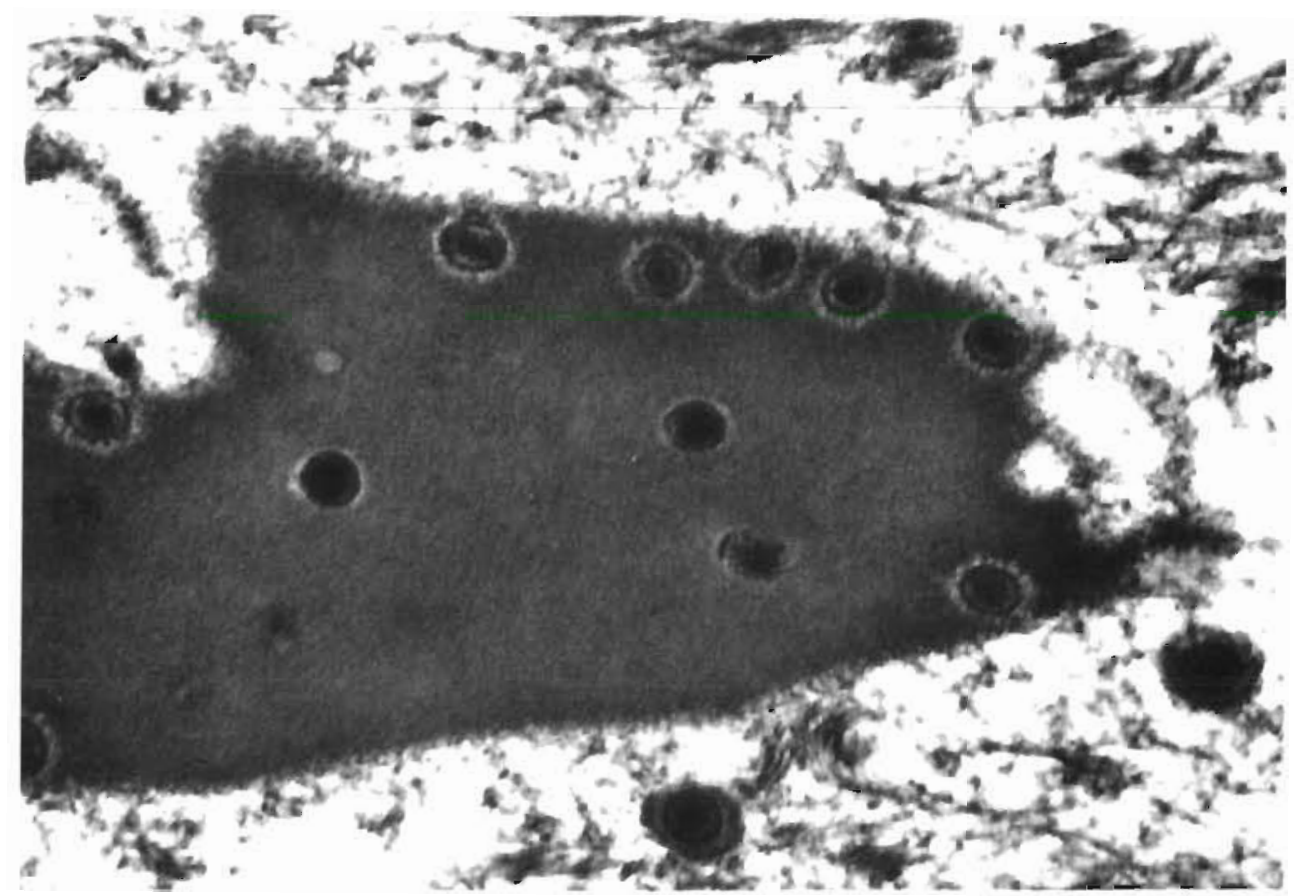

Fig. 4. Chelonia mydas. Higher magnification electron micrographs of mature particles within the cytoplasm with morphology typical of herpesvirus. $\times 91975$

uninvolved pulmonary parenchyma. There were similar areas of fibromatosis in the kidneys, with trematode eggs scattered within both affected and unaffected areas. Light microscopic examination of the 14 cutaneous fibropapillomas revealed that the surfaces were thrown into papillary projections with epidermal hyperplasia and proliferation of dermal fibroblasts. Trematode eggs were occasionally observed within dermal capillaries. In one small area of one of 14 tumors $(7 \%)$, there was ballooning degeneration of epidermal 
cells and eosinophilic intranuclear inclusions similar to those seen in Turtle No. 1.

\section{Ultrastructural findings}

By electron microscopy, intranuclear inclusions contained immature viral particles with electron-lucent and electron-dense centers; viral particles were also within adjacent areas of the cytoplasm (Fig. 3). Immature viral particles measured from 77 to $90 \mathrm{~nm}$ and obtained an envelope from the nuclear membrane. Mature, enveloped particles seen within adjacent areas of the cytoplasm measured from 110 to $120 \mathrm{~nm}$ (Fig. 4). Based upon size, location, and morphogenesis both types of particles were consistent with those of the family Herpetoviridae.

\section{DISCUSSION}

The cutaneous tumors observed in the green turtles had gross and light microscopic features typical of green turtle fibropapilloma (Jacobson et al. 1989). In addition, previously unobserved areas of epidermal ballooning degeneration, with eosinophilic intranuclear inclusions, were seen in several tumors. In Turtle No. 2, inclusions were confined to one small portion of one of $14(7 \%)$ tumors examined. This distribution indicated that for each turtle, many tumors need to be examined in order to determine the presence or absence of inclusions. The productive viral infection may only occur during very limited times in the pathogenesis of GTF.

By electron microscopy, intranuclear inclusions were found to consist of immature viral particles. In adjacent areas of the cytoplasm of infected cells, mature enveloped particles, compatible with those of herpesvirus, were observed. The only previously reported herpesviruses of green turtles are those responsible for grey patch disease (Rebell et al. 1975) and associated with a respiratory disease of green turtles at Cayman Turtle Farm, Grand Cayman, British West Indies (Jacobson et al. 1986a). The green turtles from Key West, Florida, represent the first green turtles outside of Cayman Turtle Farm to be observed with a herpesvirus infection.

Herpesviruses have been associated with and/or demonstrated to be the cause of neoplastic diseases of a variety of vertebrates including renal adenocarcinoma of the leopard frog (Lucké 1952), Marek's disease of poultry (Nanoyama 1982, Powell 1985) and Burkitt's lymphoma of humans (Werner \& Gertrude 1982). Herpesviruses have also been incriminated as the causative agent of papillomas in the European green lizard Lacerta viridis (Raynaud \& Adrian 1976) and African elephant Loxodonta africana (Jacobson et al. 1986b). However, the significance of herpesvirus as the primary pathogen versus a secondary infection can be debated. For example, while infectious bovine herpesvirus was isolated from bovine ocular squamous cell carcinomas (Sykes et al. 1961) and bovine herpesvirus-5 antigens were detected by indirect immunofluorescence in the cytoplasm of tumor cells derived from bovine ocular squamous cell carcinomas (Anson et al. 1982), a causal relationship between these bovine herpesviruses and bovine ocular tumors has not been firmly established. It is quite possible that these herpesviruses may only represent secondary infections, merely present in a growing tumor. Similarly, it is unknown whether or not the herpesvirus identified in the fibropapillomas of the green turtle of the present report is the etiologic agent of this disease. The identified virus needs to be isolated and Koch's postulates fulfilled in order to establish a causal relationship. Isolation attempts are in progress.

Trematodes of the family Spirorchidae are commonly encountered in the cardiovascular system of marine turtles and include members of the genera Amphiorchis, Carettacola, Haemoxenicon, Hapalotrema, Laeredius, Monticellius, Neospirorchis and Squaroacetabulum (Lauckner 1985). Pathological findings associated with eggs of these parasites have been described for the loggerhead sea turtle Caretta caretta (Wolke et al. 1982) and in both farmed (Greiner et al. 1980, Glazebrook \& Campbell 1990a) and wild (Glazebrook \& Campbell 1990b) green turtles.

Smith \& Coates (1939) found trematode eggs in $50 \%$ of fibro-epithelial growths on green turtles at the New York Aquarium and trematode eggs were occasionally seen within dermal capillaries of fibropapillomas of green turtles of the present report. Based upon the absence of trematode eggs in any of 28 biopsies of fibropapillomas examined from 6 green turtles, Jacobson et al. (1989) did not consider spirorchid eggs as the cause of GTF. In studies on diseases of farmed and wild marine turtles in Australia, although spirorchid trematode eggs were commonly associated with visceral granulomas in green turtles, fibropapillomas were not noted in any of the examined turtles (Glazebrook \& Campbell 1990a, b). Still, transmission studies utilizing spirorchid eggs or egg components need to be conducted in order to conclusively determine if a causal relationship exists between spirorchid eggs and tissue fibromatosis. Regardless of the role of spirorchids in GTF, the visceral tissue reactions and alterations from eggs collecting at visceral sites probably contributed to the debility of the 2 green turtles in the present report. 
Acknowledgements. We are grateful to J. Jenkins, Armed Forces Institute of Pathology, Washington, D.C., USA, for technical assistance. L. Munson, Turtle Kraals, Key West, Florida, USA for arranging the transportation of turtles, and US Air, Key West. Florida, USA for providing transportation. This report was supported by a grant from Save-A-Turtle, Marathon, Florida, USA. Published as University of Florida, Florida Agricultural Experiment Station Journal Series No. R01598.

\section{LITERATURE CITED}

Anson, M. A., Benfield, D. A., McAdaragh, J. P. (1982). Bovine herpesvirus-5 (DN599) antigens in cells derived from bovine ocular squamous cell carcinomas. Can. J. Comp. Med. 46: 334-337

Balazs, G. H. (1986). Fibropapillomas in Hawaiian green turtles. Mar. Turt. Newsl. 39: 1-3

Glazebrook, J. S., Campbell, R. S. F. (1990a). A survey of the diseases of marine turtles in northern Australia. I. Farmed turtles. Dis. aquat. Org. 9:83-95

Glazebrook, J. S., Campbell, R. S. F. (1990b). A survey of the diseases of marine turtles in northern Australia. II Oceanarium-reared and wild turtles. Dis. aquat. Org. 9: $97-104$

Greiner, E. C., Forrester, J. J., Jacobson, E. R. (1980). Helminths of mariculture-reared green turtles (Chelonia mydas mydas from Grand Cayman, British West Indies. Proc. helminth. Soc. Wash. 47: 142-144

Jacobson, E. R. (1981). Neoplastic diseases. In: Cooper, J. E., Jackson, O. F. (eds.) Diseases of the Reptilia, Vol. 2. Academic Press, London, p. 429-468

Jacobson, E. R. Gaskin, J. M., Roelke, M., Greimer, E. C., Allen, J. (1986a). Conjunctivitis, tracheitis, and pneumonia associated with herpesvirus infection in green sea turtles. J. Am. Vet. Med. Assoc. 189: 1020-1023

Jacobson, E. R., Mansell, J. L., Sundberg, J. P., Kollias, G. V., O'Banion, M. K. (1989). Cutaneous fibropapillomas of green turtles (Chelonia mydas). J. comp. Path. 101 39-52 Jacobson, E. R., Sundberg, J. P., Gaskin, J. M., Hajjar, L.,

Responsible Subject Editor: P. Zwart, Utrecht, The Netherlands
Reichmann, M. E., Ehrhart, L. M., Walsh, M., Murru, F. (1986b). Cutaneous papillomas associated with a herpesvirus-like infection in a herd captive African elephants. J. Am. Vet. Med. Assoc. 189: 1075-1078

Lauckner, G. (1985). Diseases of Reptilia. In: Kinne, O. (ed.) Diseases of marine animals, Vol. IV, Part 2. Biologische Anstalt Helgoland, Hamburg, p. 543-626

Lucké, B. (1938). Studies on tumors in cold-blooded vertebrates. Rep. Tortugas Lab. 38: 92-94

Lucké, B. (1952). Kidney carcinoma of the leopard frog: a virus tumor. Ann. N. Y. Acad. Sci. 54: 1093-1109

Nanoyama, M. (1982). The molecular biology of Marek's disease herpesvirus. In: Roizmann, B. (ed.) The herperviruses, Vol. 1. Plenum Press, New York, p. 333-346

Powell, P. C. (1985). Marek's disease virus in the chicken. In: Klein, G. (ed.) Advances in viral oncology, Vol. 5. Raven Press, New York, p. 103-127

Raynaud, M. M. A., Adrian, M. (1976). Lésions cutanées à structure papillomateuse associées à des virus chez le lézard vert (Lacerta viridis Laur). C. r. Acad. Sci., Paris 283: $845-847$

Rebell, H., Rywlin, A., Haines, H. (1975). A herpesvirus-type agent associated with skin lesions of green turtles in aquaculture. Am. J Vet. Res. 36: 1221-1224

Smith, G. M., Coates, C. W. (1938). Fibro-epithelial growths of the skin in large marine turtles, Chelonia mydas (Linnaeus). Zoologica, N.Y 23: 93-98

Smith, G. M., Coates, C. W. (1939). The occurrence of trematode ova (Hapalotrema constrictum) (Leared) in fibroepithelial tumours of the marine turtle Chelonia mydas (Linnaeus). Zoologica, N.Y 24: 379-382

Sykes, J. A., Dmochowski, L., Wynne, E. S., Russell, W O (1961). Ocular squamous-cell carcinoma. IV Tissue culture studies of bovine ocular squamous-cell carcinoma and its benign precursor lesion. J. natn. Cancer Inst. 26: 445-471

Werner, H., Gertrude, H. (1982). Immunology of Epstein-Barr virus. In: Roizman, B. (ed.) The herpesviruses, Vol. 1. Plenum Press, New York, p. 209-252

Wolke, R. E., Brooks, D. R., George, A. (1982). Spirorchidiasis in loggerhead sea turtles (Caretta caretta): Pathology. J. Wildl. Dis. 18: 175-185

Manuscript first received: June 26, 1991

Revised version accepted: August 28, 1991 